OPEN ACCESS

Edited by:

Maria Pappas,

Democritus University of Thrace,

Greece

Reviewed by:

Johan A. Stenberg,

Swedish University of Agricultural

Sciences, Sweden

Andrey S. Zaitsev

University of Giessen, Germany

*Correspondence:

François Dumont

dumont.francois.3@courrier.uqam.ca

Specialty section:

This article was submitted to Agroecology and Ecosystem Services,

a section of the journal

Frontiers in Ecology and Evolution

Received: 27 June 2018 Accepted: 04 December 2018

Published: 18 December 2018

Citation:

Dumont F, Aubry $O$ and Lucas $E$ (2018) From Evolutionary Aspects of Zoophytophagy to Biological Control.

Front. Ecol. Evol. 6:221.

doi: 10.3389/fevo.2018.00221

\section{From Evolutionary Aspects of Zoophytophagy to Biological Control}

\author{
François Dumont ${ }^{1,2 *}$, Olivier Aubry ${ }^{1}$ and Eric Lucas ${ }^{1}$ \\ ${ }^{1}$ Université du Québec à Montréal, Montreal, QC, Canada, ${ }^{2}$ Centre de Recherche Agroalimentaire de Mirabel, Mirabel, QC, \\ Canada
}

Zoophytophagy (true omnivory) is a ubiquitous behavior. It allows plant-feeding predators to maximize their development by finding essential nutrients, and to survive when animal resources are scarce. In agroecosystems, some zoophytophagous predators are highly efficient biological control agents. However, when feeding on plants, they can generate crop damage that reduce grower's interest in these predators. Artificial selection on behavioral traits of candidate zoophytophagous predators could improve the ecosystem services they provide. Thus, a zoophytophagous species considered as noxious may become an adequate biocontrol agent, following a selection process. Numerous theoretical and applied aspects should be considered during the selection process for the breeding of desired individuals. This review focuses on the potential of the evolutionary approach to optimize the biological control services provided by plant-feeding predators - or zoophytophagous predators - and discuss some ecological and biological control consequences as well as the limitations of the approach.

Keywords: artificial selection, strain selection, hemiptera, zoophytophagous predators, miridae, ecology of individuals, individual diet specialization, intraguild predation

\section{INTRODUCTION}

Numerous definitions of zoophytophagous organisms have been proposed. In this paper, we consider zoophytophagous organisms (or true omnivores) as the organisms that consume both plant and animal resources during their life cycle. In agroecosystems, these organisms may have the status of pests, equivocal species (sometimes beneficial or sometimes noxious) or useful biological control agents in agroecosystems. True omnivores can be classified along a nutritional gradient from phytozoophagous to zoophytophagous species. We consider biological control as an ecosystem service provided by zoophytophagous predators. Biological control of pest species in crop systems can be achieved using three main strategies (Eilenberg et al., 2001): (1) classical biological control, in which introduced exotic natural enemies can exert a long-term control of a targeted exotic pest; (2) augmentative biological control, where locally occurring natural enemies are reared and released to improve pest controls and (3) conservative biocontrol, in which land-use planning favors the increase of natural enemies. The augmentative strategy can be subdivided in two ways to use biological control, namely inoculative and inundative. The former aims to control pest's population over an extended period (but not permanently), whereas the latter is used to rapidly control the pest's population (over a short-term period). With the inundative strategy, no reproduction by the biological control agent is expected and repeated releases may be necessary (Eilenberg et al., 2001).

Zoophytophagous predators are a solution to the growing need for native natural enemies that efficiently control pests (McGregor et al., 1999; Alomar et al., 2006; Calvo et al., 2009; 
Fantinou et al., 2009). The role of these predators is increasingly recognized in perennial or annual cropping agroecosystems (Symondson et al., 2002). Most annual crops have multiple arthropod pest problems, requiring an array of specialists natural enemies for efficient control. These approaches are costly, and ecologically complicated due to the mutual interactions between the biological control agents. Zoophytophagous predators are highly successful because they can consume several pest species avoiding the resurgence of secondary pests (McGregor et al., 1999; Symondson et al., 2002; Alomar et al., 2006; Calvo et al., 2009, 2012; Fantinou et al., 2009; Mollá et al., 2011; Zappala et al., 2013). In addition, zoophytophagous predators have the ability to stay in an environment where prey is scarce by switching from animal resources to plant resources (Lalonde et al., 1999; Castañé et al., 2009; Castañe et al., 2011).

Despite their significant success as generalist predators, the use of zoophytophagous predators as biological control agents remains mitigated by the perceived risk of crop damage entailed by phytophagy. However, phytophagous behavior is beneficial for the predators early establishment and survival when prey is scarce (Gabarra et al., 2004; Castañe et al., 2011). Switching diet contributes to the stabilization of zoophytophagous populations, leading to sustained high predation pressure on prey populations (Diehl and Feißel, 2000). Moreover, phytophagy does not always lead to crop damage and economic loss (Castañe et al., 2011). Therefore, there is currently an increasing recognition of the potential of zoophytophagous predators in biological control (Albajes and Alomar, 1999; Wheeler, 2000; Lucas and Alomar, 2002; Urbaneja-Bernat et al., 2013; Maselou et al., 2014; Beitia et al., 2016; Pérez-Hedo et al., 2018).

The efficacy of zoophytophagous predators is affected by an array of different factors at the individual, the population and the community levels. These factors are intimately linked to plasticity and trade-offs related to the diet of zoophytophagous predators. The degree of the phenotypic plasticity of the zoophytophagous predators could be manipulated by selection processes. Therefore, artificial selection may improve traits related to their efficiency as biological control agents in their specific biotic and abiotic conditions.

We argue that the potential of the zoophytophagous predators as biocontrol agents could be enhanced by artificial selection on various traits including detrimental phytophagy, beneficial zoophagy, and diet specialization. In this review paper, we review artificial selection of biological control agents and propose hypotheses on the ecological and biological control consequences. We focus on the biological control services provided by the zoophytophagous predators at the individual, population, and community levels.

\section{THE COMPLEX ZOOPHYTOPHAGOUS PREDATORS CONTEXT AND THE BIOLOGICAL CONTROL SUCCESS}

The ability of zoophytophagous predators to provide effective biocontrol services is determined by an array of biological responses observed at different ecological levels. The value of zoophytophagous predators is not simply linked to their zoophagous abilities as biological control agents (i.e., zoophagy on agricultural pests) (McGregor et al., 1999; Castañé et al., 2009; Calvo et al., 2012; Zappala et al., 2013), but also to their relative detrimental impact as phytophagous organisms (Arnó et al., 2006, 2010; Calvo et al., 2009; Perdikis et al., 2009; Castañe et al., 2011). The classification of true omnivores as zoophytophagous or phytozoophagous is often subjective (Wiedenmann and Wilson, 1996). The term used reflects the perception of the observer (ecologist, agronomist) rather than the actual proportion of resources consumed. For example, several zoophytophagous bugs (plant-feeding predators) (Coll and Guershon, 2002) are successfully used as biological control agents of greenhouse and outdoors pests (Castañé et al., 1996, 2009; McGregor et al., 1999; Alomar et al., 2006; Calvo et al., 2009, 2012; Fantinou et al., 2009; Mollá et al., 2011; Zappala et al., 2013). However, the status of zoophytophagous predators in the agroecosystem is controversial because they may cause crop damage and economic losses. Therefore, to fully exploit the potential of zoophytophagous predators, we have to develop methods that improve the benefit-damage ratio associated with their occurrence on crops (Castañe et al., 2011; Calvo et al., 2012). The optimization of zoophytophagous predators for biological control entails complex interactions between predator's morphological, physiological and behavioral traits and the ecological context.

Since animal and plant diets differ greatly, omnivores display physiological and morphological adaptations that are normally only present in strict zoophagous or strict phytophagous insects (Cooper, 2002; Cooper and Vitt, 2002; Eubanks et al., 2003). For example, zoophytophagous mirids have intermediate stylets between those of strongly toothed zoophagous and those relatively smooth of phytophagous insects (Cobben, 1978; Schaefer and Panizzi, 2000). Roitberg et al. (2005) demonstrated that there may be a cost to be zoophytophagous due to the mandibles being worn out by consuming plants. Stylet wear could reduce predation efficiency, compelling an increase in phytophagy. Omnivorous Heteroptera have also a digestive system and accessory salivary glands that are intermediate to those found in herbivores or predators (Boyd et al., 2002), as well as digestive enzymes from both groups (Schaefer and Panizzi, 2000; Wheeler, 2001). Because of these adaptations, zoophytophagous predators have more detoxifying enzymes, improving the ability to manage secondary toxic compounds. They should therefore be more resistant to certain pesticides than strict predators (Gordon, 1961; Coll et al., 1994; Coll and Guershon, 2002). This resistance may improve their ecosystem services in integrated pest management (IPM) programs.

Behavioral plasticity is mainly responsible for the biological control effect of zoophytophagous predators (Coll and Guershon, 2002). For example, Aubry et al. (2017) demonstrated that Campylomma verbasci Meyer-Dür (Hemiptera: Miridae) reduce phytophagy (measured as plant feeding punctures) in presence of prey (aphids or spider mites). In this species, most of the damage on apple fruits is caused by the overwintering population during bloom (Aubry et al., 2016). However, adults tend to leave apple trees once the prey population is depleted. The mullein 
bug is no longer noxious after bloom as plant-feeding does not induce fruit damage (for fruits $>13 \mathrm{~mm}$ ) and its status becomes beneficial (Aubry et al., 2016). This shift is also observed in other mirids species in open field and greenhouse conditions (Gabarra et al., 2004; Montserrat et al., 2004; Sanchez, 2008), and successfully used to develop management decision charts for Dicyphus tamaninii Wagner (Hemiptera: Miridae) in tomato crops (Alomar and Albajes, 1996) or C. verbasci in apple orchards (Coll, 1996).

The potential impact of omnivores on prey (noxious or beneficial status) depends not only on their ability to persist during prey scarcity, but also on their response when the consumption of alternative plant and animal resources decreases their prey consumption (Cottrell and Yeargan, 1998; Eubanks and Denno, 2000b). For example, nutrition on high quality plant resources can result in relatively large and persistent populations of omnivores (Eubanks and Styrsky, 2005). By contrast, strict predators will either starve or migrate when their prey is scarce, allowing prey to escape predation at low densities and populations to rebound (Eubanks and Styrsky, 2005).

At the community level, plant-feeding and prey-feeding decisions have important implications for predator-prey dynamics, for energy flows within food webs (Lalonde et al., 1999; Coll and Guershon, 2002) and, consequently, for the noxious/beneficial status of the zoophytophagous predators. Omnivory disperses the direct effects of consumption throughout the trophic web, rather than concentrating them at a specific trophic level (Eubanks, 2005) which favors larger, persistent and often less variable populations. When prey populations decline, omnivores can move to relatively profitable plants providing a mechanism that promotes the stability of the communities (Gillespie et al., 2012). Thus, phytophagy from zoophytophagous predators should promote bottom-up control and increase the likelihood of trophic cascades (Eubanks and Denno, 1999, 2000b; Denno and Fagan, 2003) which will ultimately benefit the plant (Eubanks, 2005).

Intraguild predation (IGP) is defined as predation between species sharing a similar resource (Lucas, 2012) and can also alter the feeding behavior, the development, and the biological control services of zoophytophagous species (Rosenheim et al., 1993; Rosenheim and Harmon, 2006; Vance-Chalcraft et al., 2007). An increase in extraguild prey density should reduce IGP by providing alternative prey options, regardless of intraguild predator density (Lucas and Rosenheim, 2011; Lucas, 2012). Aubry et al. (2017) showed that the presence of extraguild prey reduces phytophagous behavior in the mullein bug $C$. verbasci even in the presence of some intraguild predators. Aubry et al. (2017) suggested that the reduction in feeding punctures might have been caused either by predation on mullein bugs or by a change in behavior of the mullein bug (e.g., escaping, hiding). Concerning the zoophagous impact on the prey population, Lucas and Alomar (2002) showed that the presence of an IGP predation delayed the development of the zoophytophagous Macrolophus caliginosus Wagner (Hemiptera: Miridae). The guild context can greatly change the propension to attack plants or prey and the status of a zoophytophagous predator.

\section{TOWARD ARTIFICIAL SELECTION}

The last two decades have been marked by a significant increase in knowledge in ecology of individuals (Bolnick et al., 2002; Dall et al., 2004, 2012; Dingemanse et al., 2010; Réale et al., 2010a,b; Ellner, 2013). The ecology of individuals aims to integrate intraspecific phenotypic variation in ecological models (Judson, 1994; Grimm, 1999; Łomnicki, 1999; Clutton-Brock and Sheldon, 2010; Bolnick et al., 2011; Wolf and Weissing, 2012). The later models focus on the mainstream response of the focal population while discarding individual variations. These models are often based on the premise that individuals are interchangeable or have the capacity to adapt optimally to all situations (Sih et al., 2004). However, it has been demonstrated in several taxonomic groups that behavioral differences among individuals have considerable ecological consequences (Sih et al., 2004, 2012; Réale et al., 2007; Araújo et al., 2011; Bolnick et al., 2011). Recently, some studies have demonstrated that native biological control agents can be improved by exploiting intraspecific behavioral differences in various traits related to their efficiency (Lommen et al., 2008, 2013; Tabone et al., 2010; Nakayama et al., 2013: Seko et al., 2014; Dumont et al., 2016, 2017a). Therefore, some authors (Hoy, 1986; Rosenheim and Hoy, 1988; Hopper et al., 1993; Nachappa et al., 2010, 2011; Lommen et al., 2013, 2017; Dumont et al., 2016, 2017a; Kruitwagen et al., 2018) suggested that genetic improvement of biocontrol agents could rely on intraspecific behavioral differences.

The first successful examples of genetic improvement of biocontrol agents were intended to increase their pesticide resistance (Hoy and Knop, 1981; Hoy, 1985, 1986, 1990; Rosenheim and Hoy, 1988; Havron et al., 1991). More recently, intraspecific behavioral variations are of interest to researchers especially in nematodes (Segal and Glazer, 2000; Shapiro-Ilan et al., 2003), mites (Pels and Sabelis, 1999; Jia et al., 2002; Maeda and Liu, 2006; Nachappa et al., 2010, 2011), coccinelids (Tourniaire et al., 2000; Lommen et al., 2008; Seko and Miura, 2009; Adachi-Hagimori et al., 2011) and parasitoid wasps (Baya et al., 2007; Kruitwagen et al., 2018). The performance (as biological control agent) of native predators and parasitoids has been improved in the control of their natural or exotic prey (Kraaijeveld et al., 2001; Rouchet and Vorburger, 2014). Recently, the concept of genetic improvement applied to zoophytophagous predators arouses a growing interest. Dumont et al. (2016, 2017a) used this approach on the mullein bug, but this species is not commercialized as biological control agent. It is even considered as a pest species by some authors (Thistlewood et al., 1989; McBrien et al., 1997).

A biocontrol strategy that relies on zoophytophagous predators should aim to increase their effectiveness while minimizing their detrimental behavior. The emerging field of genetic improvement on biocontrol agents offers a promising avenue for achieving these goals (Dumont et al., 2016, 2017a;). Dumont et al. (2016, 2017a) reported genetic variations in zoophagy and individuals' diet specialization in mullein bug. Thus, these authors suggested that zoophytophagous populations are in fact composed of a mix of individuals specialized, to some degree, on animal or plant diet. Therefore, it is possible 
to manipulate the composition of zoophytophagous predator's population by artificial selection by favoring prey-specialized individuals over more plant-specialized ones (Dumont et al., 2017a; Kruitwagen et al., 2018). Hence, it could increase these predators' efficiency as biocontrol agents and/or reducing the risk of damage.

\section{TRAITS TO TARGET WITH SELECTION IN ZOOPHYTOPHAGOUS BUGS}

The genetic improvement process can target several traits (i.e., morphology, physiology, behavior and life history traits) of biological control agents to optimize their effectiveness (Hoy, 1976; Rosenheim and Hoy, 1988; Lommen et al., 2017). In zoophytophagous predators, we propose that selection should target feeding behaviors, such as zoophagy and phytophagy. The feeding behavior of zoophytophagous predators is motivated among others by the need of water, nutrient complementarity, response to resource availability and quality and risks of predation (Gillespie and McGregor, 2000; Coll and Guershon, 2002; Lemos et al., 2009; Portillo et al., 2012). Hence, the selection process can target many traits related to feeding behavior. Heritable genetic variation in targeted traits is required to operate selection. The phenotype (i.e., behavior or life-history traits) results from the interaction between the genotype and the environment. The selective breeding in zoophytophagous predators should occur in condition representative of the field and under which the targeted trait is beneficial/detrimental.

Zoophytophagous predators have the ability to adjust their level of zoophagy and phytophagy according to the environmental conditions and the quality and availability of food resources (Calvo et al., 2009; Aubry et al., 2016, 2017). The premise underlying genetic improvement in these predators is that phenotypic plasticity may be limited, expensive (in term of fitness), often requires a trade-off and has a genetic basis (DeWitt et al., 1998; Scheiner and Berrigan, 1998; Agrawal et al., 2002). The behavioral type of individuals (also called "animal personality" or "behavioral syndrome") is described as interindividual differences maintained over context and time (Réale et al., 2007; Sih et al., 2012; Toscano et al., 2016). Individuals respond to environmental conditions (exhibiting phenotypic plasticity), but individual differences in this response demonstrate that phenotypic plasticity is not infinite (Dingemanse et al., 2010; Dingemanse and Wolf, 2013). Thus, the selection we propose would not transform a population of zoophytophagous predators into a strict predator. Selected individuals will always have the ability to exploit animal and plant resources and adjust to changing conditions. The proposed selection focuses on genetic differences in behavioral plasticity.

\section{Decreasing Detrimental Phytophagy}

Zoophytophagous bugs feed on plants to meet different needs, namely water, nutrients and proteins (Gillespie and McGregor, 2000; Lemos et al., 2009; Portillo et al., 2012; Urbaneja-Bernat et al., 2013). While damage can be caused by plant feeding, phytophagy is not always detrimental (Castañe et al., 2011). The specific plant structure providing the required resources is highly determining the level of damage resulting from phytophagy (Castañe et al., 2011). For example, the consumption of pollen, a food source rich in protein, can fill a need in the absence of prey without necessarily causing an increase in damage. In addition, crop damage may depend on the phenological stage of the plant or cultivar (Aubry et al., 2016). Therefore, damage results from a complex interaction among the biological agent's traits, plant species and environment (Castañe et al., 2011). For an effective selection on phytophagy, it is necessary to understand these interactions that lead to the consumption of certain plant parts (those that generate crop damage) (Castañe et al., 2011). Castañe et al. (2011) report that stylet morphology or saliva composition does not generate differences in damage caused by four different species of mirids [D. tamaninii, Dicyphus Hesperus Knight (Hemiptera: Miridae), Macrolophus pygmaeus (Rambur) (Hemiptera: Miridae), and Nesidiocoris tenuis (Reuter) (Hemiptera: Miridae)]. Therefore, differences in damage could rather be caused by bugs behavior, resource preferences and response to conditions (Castañe et al., 2011). Hence, the first step of a genetic improvement program would be to identify the conditions that lead to crop damage and, then, target the predator's phytophagous traits that modulate the response to these conditions.

\section{Increasing Beneficial Zoophagy}

An increase in zoophagy without increasing detrimental phytophagy would enhance the benefit-damage ratio in zoophytophagous predators. Dumont et al. (2016) observed significant genetic variation in zoophagy in mullein bugs. Mullein bug's lines that were highly zoophagous on spider mites were also more zoophagous on aphids (Dumont et al., 2016). However, extraoral digestion requires a substantial amount of water for the considerable amount of digestive enzymes injected into zoophytophagous predator's prey and also to maintain their physiological status (Sinia et al., 2004; Castañe et al., 2011). Hence, there is always a level of phytophagy with predation (Aubry et al., 2017). An increase in zoophagy can be positively correlated with phytophagy (Sinia et al., 2004). Sinia et al. (2004) observed that $D$. hesperus individuals provided with prey (eggs of Ephestia kuehniella Zeller; Lepidoptera: Pyralidae) fed more frequently on plants than individuals deprived of animal resources. Nevertheless, several studies demonstrated that the phytophagy tends to be constant and not related to the level of zoophagy (Salamero et al., 1987; Gillespie and McGregor, 2000; Sanchez, 2008; Aubry et al., 2017). Thus, phytophagy should probably be considered essential rather than facultative (Castañe et al., 2011; Aubry et al., 2017). However, the relationship between zoophagy and water requirement may not be linear and could be modulated by the type of resource consumed (e.g., size of the prey, water content in the prey, etc.). This relationship would have to be understood to improve zoophytophagous bug's level of zoophagy.

Zoophagy is the result of a series of behaviors that lead to the consumption of prey. The predator must find and identify its prey, capture it, kill it and consume it. A change in efficiency in any of these components of predation would generate an 
increase or a decrease in zoophagy. A selection on components of predation behavior did increase the benefits provided by the specialist mite predator Phytoseiulus persimilis Athias-Henriot (Acari: Phytoseiidae) (Nachappa et al., 2010, 2011). Nachappa et al. (2011) demonstrated that selected lines of P. persimilis with high levels of prey consumption, conversion efficiency or olfactory response were more efficient in controlling spider mites in the field compared to a commercial population. Applying similar selection on zoophytophagous predators could lead to significantly different results, especially on their stability over a long-term period. Even after selection for higher zoophagy, zoophytophagous predators would still be able/need to feed on plant tissue. The response of highly-zoophagous strains to conditions of prey scarcity would have to be determined to ensure that the benefit-damage ratio is in fact enhanced.

Aggressiveness influences predator-prey interactions (Riechert and Hedrick, 1993). The more aggressive the predators, the more zoophagous they will be (Riechert and Hedrick, 1993). Hedrick and Riechert (1989) observed that aggressive desert spiders Agelenopsis aperta Gertsch (Araneae: Agelenidae) (measured as attack latency) exhibited a higher frequency of attack than non-aggressive individuals toward several prey. Aggressiveness in A. aperta spiders is genetically determined (Hedrick and Riechert, 1989). Moreover, high level of aggressiveness leads to wasteful killing (Maupin and Riechert, 2001). Increasing aggressiveness in zoophytophagous predators could result in more zoophagy (both in frequency of attacks and range of prey attacked) and wasteful killing. Dumont et al. (2016) reported some degree of wasteful killing in C. verbasci belonging to highly zoophagous lines. In zoophytophagous predators, wasteful killing is interesting to increase the benefit-damage ratio. Bugs may not invest as much extra oral digestive enzymes in unconsumed prey (wasted prey) as in fully consumed prey. Therefore, the relationship between the number of prey killed (zoophagy) and water requirement could be modulated by selection on aggressiveness.

\section{Optimizing Zoophytophagous Predators Through Diet Specialization}

Individual differences in morphological, physiological, and behavioral traits can generate diet specialization (i.e., when individuals use only a subset of the resources consumed by the whole population) (Bolnick et al., 2002; Toscano et al., 2016). This diet specialization occurs when individuals respond differently to ecological and environmental factors (e.g., predation risk and intraspecific competition) or when individuals differ in their efficiency in exploiting available resources (Svanbäck and Bolnick, 2005; Araújo et al., 2011; Toscano et al., 2016). Sokolowski (2001) argues that the link between genotype and foraging behavior is complex and depends on the effect of several genes. This complexity can generate considerable inter-individual differences in the resource consumption choice. The resource choice of the individuals reflects their ability to deal with these resources (Bolnick et al., 2002). Therefore, different phenotypes in the population would perform better in the exploitation of some resources. These differences would constitute a form of individual specialization in ecological niches (Bolnick et al., 2002). Such differences in specialization would be maintained in populations by different factors, including heterogeneous spatial and/or temporal abundance, availability and quality of resources (Jaenike and Grimaldi, 1983; Wilson and Yoshimura, 1994; Svanbäck and Bolnick, 2005; Araújo et al., 2011. The variations could be exploited as part of a zoophytophagous predator improvement program (Dumont et al., 2016, 2017a).

In zoophytophagous predators, diet specialization can be expressed in different ways depending on the availability of resources. For example, Dumont et al. (2017a) have observed that when prey (spider mites) and pollen (a major source of plant protein) are simultaneously available, some strains of mullein bugs feed mainly on prey while others have a diet exclusively composed of pollen, expressing their food specialization. In the absence of pollen, the strain specialized on this resource generally had a lower zoophagy level than the strain specialized on animal resources (Dumont et al., 2017a). However, the food specialization observed by Dumont et al. (2017a) does not necessarily point out a benefit-damage gradient on which their strains could be classified. Pollen consumption does not generate crop damage (Torres et al., 2010; Aubry et al., 2016).

In zoophytophagous predators, the diversity of food resources requires an ability to cope with many complex information that may exceed their cognitive abilities (Bernays, 1996). Such a diversity of information to process is likely to lead to food and host specialization (Bernays and Wcislo, 1994). The processing of complex information would be costly for zoophytophagous predators in terms of decision time, assessment of food quality and oviposition site selection (Bernays and Wcislo, 1994; Bernays and Bright, 2001). Bernays et al. (2004) find that generalist (phytophagous) species spend more time dispersing and assessing resources and have shorter feeding bouts compared to specialists. The food specialization resulting from information management could be genetic (Dumont et al., 2017a) and/or be the result of previous experience (Lins et al., 2014; Rim et al., 2017; Lima-Espindola et al., 2018). An alternative strategy to complex information management for omnivorous predators would be to be less selective and more opportunistic. Opportunistic predators would be more likely to attack prey regardless of their quality (Eubanks and Denno, 2000a). The genetic improvement of zoophytophagous predators for biological control could be through selection on a specialization in the management of relevant information (e.g., specific prey detection) or predator responsiveness to prey.

\section{SELECTION CONSEQUENCES ON ECOLOGICAL INTERACTIONS}

The feeding behavior of zoophytophagous predators is modulated by their interaction with the host plants (Sanchez et al., 2004; Aubry et al., 2016; Biondi et al., 2016), prey (Biondi et al., 2016; Aubry et al., 2017) and/or intraguild predators/competitors (Lucas and Alomar, 2001, 2002; Perdikis et al., 2014; Aubry et al., 2017). Thus, the zoophytophagous 
predators responses to biotic conditions will influence the predator population mean value. However, individual behavioral differences cause variation around this mean depending on individual's characteristics and population composition (Sih et al., 2012). The individuals' functional role at the population and community levels may differ according to their behavioral type and diet (Sih et al., 2004, 2012; Hughes et al., 2008; Araújo et al., 2011; Bolnick et al., 2011; Pruitt and Ferrari, 2011). The inherent ecological variation caused by selection would in turn influence their application to biological control.

\section{Interactions With Host Plants}

Host plants play a central role in the success of zoophytophagous predators, as they provide both food resources (e.g., water, carbohydrates, proteins), habitat for their prey and substrate for egg laying (Sanchez et al., 2004). A selection on the feeding behavior (i.e., phytophagy, zoophagy, diet specialization) of zoophytophagous predators will modulate host preference for nutrition and oviposition. These predators use various cues related to plant quality and prey availability to discriminate and select their host (Coll, 1996; Eubanks and Denno, 2000a,b; Grosman et al., 2005; Lins et al., 2014; Ingegno et al., 2016). For instance, zoophytophagous predators are attracted to volatiles from prey-infested plants (herbivore-induced plant volatiles; HIPVs) (Lins et al., 2014; De Backer et al., 2015; Silva et al., 2018). Lins et al. (2014) observed that both M. pygmaeus and N. tenuis responded positively to plants infested by their prey [whitefly Bemisia tabaci Gennadius (Hemiptera: Aleyrodidae) and the tomato borer Tuta absoluta Meyrick (Lepidoptera: Gelechiidae)]. Moreover, experienced predators are more reactive to plant volatiles than naïve individuals (Lins et al., 2014; Rim et al., 2017; Lima-Espindola et al., 2018). Hence, prey-specialized or highly-zoophagous individuals could be more reactive to HIPVs than their plant-specialized or lowly-zoophagous counterpart due to 1) increased experience with hosts infested with prey and/or 2) genetic correlation between zoophagy and olfactory response to HIPVs (Nachappa et al., 2010). In contrast, plantspecialized bugs could rather rely on cues related to plant quality to choose their host. The same cues could be used by ovipositing females to find sites to lay their eggs (Sanchez et al., 2004). Females tend to select oviposition sites to optimize their offspring survivorship and performance (Coll, 1996; Seagraves and Lundgren, 2010). The result would be a spatial distribution of zoophytophagous predators that reflects their food specialization. In the agricultural environment, the plants infested by pests could be least interesting for the plant-specialized bugs due to plant's depletion or plant's defensive mechanisms, whereas they would be the most interesting for the prey-specialized ones.

Phytophagy in zoophytophagous predators can trigger plant defensive responses, such as the emission of HIPVs or the expression of defense-related genes (Pappas et al., 2015, 2016; Pérez-Hedo et al., 2015a, 2018; Naselli et al., 2016; Bouagga et al., 2018a). Zoophytophagous predator's prey or competitors (i.e., parasitoid wasps) can be responsive to these HIPVs (Bouagga et al., 2018a). These interactions vary, however, depending on the species involved (Perez-Hedo et al., 2015b). For instance, plant feeding by the zoophytophagous bug $N$. tenuis activated both abscisic and jasmonic acids in tomato plants, which repel both B. tabaci and T. absoluta (Pérez-Hedo et al., 2015a). However, $B$. tabaci is not repelled by plant where M. pygmaeus and Dicyphus maroccanus Wagner (Hemiptera: Miridae) had been feeding (Perez-Hedo et al., 2015b). The tomato borer T. absoluta is even attracted by the plant on which M. pygmaeus and D. maroccanus fed (Perez-Hedo et al., 2015b). Moreover, the whitefly parasitoid Encarsia formosa Gahan (Hymenoptera: Aphelinidae) is attracted to plant volatiles emitted in response to zoophytophagous bugs phytophagy (Pérez-Hedo et al., 2015a; Bouagga et al., 2018a). Therefore, phytophagy by zoophytophagous predators can enhance plant protection against main pests (Bouagga et al., 2018b). Selection to favor lowly-phytophagous strains would thus reduce this advantage provided by zoophytophagous predators. However, even a low level of phytophagy or non-detrimental phytophagy could induce HIPVs from host plants (Pérez-Hedo et al., 2015a, 2018).

Phytophagy by zoophytophagous predators can induce direct plant defense responses against herbivores (Pappas et al., 2015). Pappas et al. (2015) observed that phytophagy by the zoophytophagous predator $M$. pygmaeus triggers a defensive response in tomato that is effective against a subsequent infestation of the two-spotted spider mite Tetranychus urticae Koch (Acari: Tetranychidae). This defensive mechanism was, however, ineffective against greenhouse whitefly Trialeurodes vaporariorum Westwood (Hemiptera: Trialeurodes) (Pappas et al., 2015, 2016). Zoophytophagous predators may therefore have indirect biological control effect over certain prey. A selection that reduces phytophagy in a zoophytophagous predator will result in minimizing this path by which the predator can affect their prey. In addition, plants defensive responses can be induced by an endophytic fungus, and reduce damage from both zoophytophagous predators (Garantonakis et al., 2018) and pests (Pappas et al., 2018). Garantonakis et al. (2018) observed less damage from the zoophytophagous predator $N$. tenuis on tomato plants inoculated with the fungal endophyte Fusarium solani strain $\mathrm{K}$ than on uninoculated plants. The authors have not determined whether the symbiosis between the plant and the fungal endophyte confers on the plant the ability to repair damage or repel $N$. tenuis (reduction of phytophagy). In the first case, more zoophagous (but not necessarily less phytophagous) lines would be very useful in biological control. These strains would increase the level of benefits by consuming more prey without proportionally increasing damage. In the second case (the plant-fungus symbiosis repelling the zoophytophagous predator), strains specialized in prey resources may be less sensitive to this plant defense mechanism than more phytophagous strains. Inoculation of the plants with beneficial soil microorganims may be a method of control compatible with the release of prey-specialized zoophytophagous predator stains.

Phytophagy is not necessarily detrimental depending on the plant material consumed and the plant and omnivore phenology (Castañe et al., 2011; Aubry et al., 2015, 2016). In many omnivores, the combined effect of consuming two types of resources can improve their diet nutritional quality of the diet. This synergistic effect (trophic facilitation) can strongly affect their selective value (Waldbauer and Friedman, 1991; Singer and 
Bernays, 2003) and consequently their use as biocontrol agents. For example, the spring generation of $C$. verbasci's nymphs hatching on apple trees can feed on apple fruit supplemented by pollen or prey to reach adulthood (Aubry et al., 2015). Plant resources can also have a synergistic effect on prey consumption (Eubanks, 2005). Predaceous Hemipteran need a substantial amount of water for predation which can be provided by plant tissue (Gillespie and McGregor, 2000; Han et al., 2015). Indeed, a certain level of phytophagy by $C$. verbasci is always observed even in the presence of prey (Aubry et al., 2017).

\section{Interactions With Prey}

At the population level, several models predict that omnivores may have a greater suppressive effect on prey populations than strict predators (Polis, 1991; Holt and Lawton, 1994; Holt and Polis, 1997). Unlike strict predators, omnivorous predators compete with their prey for the shared plant resource (Diehl and Feißel, 2000) and are unlikely to starve or migrate when prey is rare because they feed at more than one trophic levels (Eubanks and Denno, 1999). In fact, the shared plant contributes to the maintenance of a greater predation pressure on the herbivorous prey by favoring a larger and more stable omnivore population density (Diehl and Feißel, 2000). The competition between prey and individuals from selected strains (highly zoophagous or preyspecialized strains) for plant resources should be negligible. In the presence of prey, the predator should feed on it rather than alternative plant resources. Phytophagy by the predator would not be intensive enough to generate high level of competition with its prey. The omnivorous predator will maintain its advantage over strict predators despite selection on zoophagy and food specialization since it will always be able to supplement their diet with plant resources. These resources would only be a smaller proportion of their diet.

An increase in prey consumption in zoophytophagous predators would translate into an increase in predations risk for the prey. High prey consumption and diet specialization on prey can result from a high level of activity (Toscano et al., 2016; Start and Gilbert, 2017). Thus, the rate of encounters with the prey and the rate of attacks against them would increase with the level of activity of the predator. In response to this increase in predation risk, prey can adopt costly strategies to avoid predators (Preisser et al., 2005). Preisser et al. (2005) estimated that prey demography was as impacted by intimidation (indirect effect of predation) as direct consumption. Prey could avoid predation by selecting host plants less favorable for their zoophytophagous predators (Bernays and Graham, 1988). However, this strategy may be less effective against zoophytophagous predator strains specialized in animal resources. The success of such strains would depend less on their host plants than strains that include more plant resources in their diet.

\section{Interactions With Competitors and Intraguild Predation}

Intra- and interspecific competition among natural enemies could be altered by selection on diet specialization, high zoophagy and aggressiveness. In the first place, all these traits can be correlated to individual levels of competitiveness. More aggressive individuals are usually better competitors and can use a higher proportion of resources or prevent other individuals to exploit them (Bolnick et al., 2002, 2011; Svanbäck and Bolnick, 2005, 2007; Pruitt and Ferrari, 2011; Pruitt and Riechert, 2012; Sih et al., 2012). In the case of zoophytophagous predators, since more aggressive individuals are expected to be more zoophagous, highly-zoophagous strains could be more competitive on prey resources than phytophagous strains. Therefore, highlyzoophagous strains would have potential strong impact on interspecific competitors. In various crop systems, different zoophytophagous species naturally colonize the plants (Albajes and Alomar, 1999; Montserrat et al., 2000; Alomar et al., 2002). For instance, Dicyphus maroccanus and N. tenuis are both present on tomato plants in eastern Spain (Salas Gervassio et al., 2017). However, $N$. tenuis tends to displace $D$. maroccanus from plants because of higher competitive abilities. A selection to increase $N$. tenuis level of zoophagy would only exacerbate this situation, whereas such selection on $D$. maroccanus could allow a better equilibrium between both species. Similarly, highly-zoophagous strains would increase intraspecific competition resulting in a potential diet switch in less competitive individuals (Robinson and Wilson, 1998; Bolnick, 2001; Araújo et al., 2009).

Zoophytophagous predators are often found in systems with other biological control agents. Most commonly with other zoophytophagous predators (Lucas and Alomar, 2001, 2002; Perdikis et al., 2014) or parasitoid wasps (McGregor and Gillespie, 2005). For instance, D. hesperus bugs and parasitoid wasps can be used simultaneously in a greenhouse to increase the impact on whitefly populations (McGregor and Gillespie, 2005). Together, biological control agents lead to larger decrease in pest populations (Bennett et al., 2009). However, D. hesperus bugs reduce both the density of whitefly populations and extend a more scattered distribution or prey (Bennett et al., 2009). Under these conditions, the parasitoid wasp E. formosa is less effective (Bennett et al., 2009). The level of the predator's zoophagy has an impact on the distribution or prey. More zoophagous strains tend to eliminate all prey from one patch before searching for and exploiting another patch (Nachappa et al., 2011). The result is a prey distribution that included less patch but with denser prey densities in these. A selection to increase the zoophagy level of the predator. D. hesperus could modulate the distribution of prey so as to favor the cohabitation between $D$. hesperus and E. formosa.

Increased zoophagy could be associated with an increase in the level of predation risk. The highly-zoophagous individuals should spend more time on parts of the plants where prey is numerous (e.g., leaves). These prey would attract other predators, which can in turn be intraguild predators of zoophytophagous predators (Lucas et al., 1998; Lucas and Alomar, 2001; Fréchette et al., 2007). Therefore, the choice of resources for zoophytophagous predators should affect the level of risk and the rate of encounter with predators. Moreover, zoophagy and aggressiveness is positively correlated with boldness (the level of risk taken in presence of predators) (Riechert and Hall, 2000; Sih et al., 2012). However, intraguild predators among zoophytophagous predators may be limited (Perdikis et al., 2014). 
In some situations, zoophytophagous predators are intraguild predators in IGP interactions (Snyder and Ives, 2003; Bennett et al., 2009). For instance, D. hesperus kills the parasitoid wasps E. formosa pupae when feeding on parasited whiteflies (Bennett et al., 2009). Highly-zoophagous or prey-specialized D. hesperus strains could have a stronger impact on a parasitoid wasp's population than strains that rely more on plant food resources. The consequences would be that genetic improvement of zoophytophagous predators for a higher level of zoophagy is not consistent with a biological control program involving several types of predators. However, the negative impact of predation on intraguild prey may not always disrupt biological control (Snyder and Ives, 2003). Snyder and Ives (2003) observed that generalist bugs Nabis sp. (Hemiptera: Nabidae) and Orius sp. (Hemiptera: Anthocoridae) decrease populations of parasitoid wasps by about $50 \%$ but the impact of these biological agents on aphid's populations was additive.

\section{IMPACT ON BIOLOGICAL CONTROL: BENEFITS AND CHALLENGES}

Genetic improvement of biocontrol agents can be adapted to different biological control strategies. The strategy will depend on the crop (e.g., perennial or annual), the targeted pests, the environment (e.g., field or greenhouse) and the biological control agents. Different strains of the same biological control agent could meet different needs or be better adapted to different conditions. Thus, genetic improvement can serve all types of biological control approaches (i.e., inoculative, inundative and conservation). However, understanding the impact of zoophytophagous predators at the population and community levels is needed to predict the effects of selection on their efficiency as biological control agents on the long term.

\section{Inundative Strategy}

Improving biocontrol agents would be more suitable for the inundative strategy (Lommen et al., 2017). Highly-zoophagous or prey-specialized strains could provide rapid and strong impact sought after by the inundative biocontrol strategy (Nachappa et al., 2011). For instance, high level of conversion efficiency and dispersal in the specialist predatory mite $P$. persimilis were associated with better spatio-temporal correlation between the predator and the prey (Nachappa et al., 2011). The authors suggested that all three selected lines achieve biological control objectives by using different paths. However, these paths may not be all stable over a long period (Nachappa et al., 2011). The study by Nachappa et al. (2011) suggests that different strains could be developed to fit different biological control needs. For instance, highly-zoophagous strains could provide rapid and intense decrease in pest populations, but at the cost of lower stability on the long run. In the case of zoophytophagous predators, obtaining a strong, rapid and localized impact on pest's population resulting from the use of highly zoophagous strains would allow to achieve these objectives while releasing fewer individuals than with a generic population (Dumont et al., 2016). As the risks of damage increase when the density of predators and their prey is high, fewer individuals would mean less risk during periods of low prey level. Thus, once predators have significantly reduced pest populations, there will be fewer zoophytophagous predators to cause damage. Moreover, the response of the selected strains to the various conditions is important in determining their value as biological control agents. Under conditions of prey scarcity, zoophytophagous predators will either turn to plant resources, cannibalism or disperse elsewhere to find their prey. In the case of a prey-specialized strain, the last two options are more likely. However, both options will have the effect of reducing zoophytophagous predator populations on crops, while the former option maintains (within certain limits) populations of predators in the absence of pests.

The genetic improvement approach could help promote effective zoophytophagous predators that cause significant level of damage when prey is scarce. For instance, the bug $N$. tenuis is a proven efficient biocontrol agent of major pest species in tomato greenhouses (Sanchez et al., 2004, 2014; Calvo et al., 2009; Urbaneja et al., 2009; Desneux et al., 2011; Bompard et al., 2013; Jaworski et al., 2013; Zappala et al., 2013). The release of $N$. tenuis decreased B. tabaci populations by about $90 \%$ (Calvo et al., 2009, 2012) and regulated populations of T. absoluta (Mollá et al., 2011). However, the benefit provided by $N$. tenuis on crop comes at a high cost. Once N. tenuis has successfully reduced the pest population, it increasingly feeds on the tip of the tomato plant and flowers, which cause important damage (Sanchez, 2008; Sánchez and Lacasa, 2008; Calvo et al., 2009; Arnó et al., 2010; Castañe et al., 2011). Artificial selection to decrease the level of detrimental phytophagy in $N$. tenuis would considerably increase its benefit-damage ratio. It would make it possible to use this effective predator on a larger scale without incurring the current risks. A selection on the food specialization of this predator would have a similar effect while maintaining the level of zoophagy that makes it successful as biological control agent.

Introduced biological control agents are not always adapted to local conditions, but individuals in the natural population can be (Hopper et al., 1993; Hufbauer and Roderick, 2005). In biological control, it is generally suggested to introduce genetically diversified populations, which will allow adaptation to new conditions (Hopper et al., 1993). However, artificial selection is reducing genetic diversity (Falconer and Mackay, 1996). Thus, biological control agent release could be effective in a specific condition or to achieve specific goals, but their longterm effects could be mitigated (Nachappa et al., 2011). Repeated introductions may be necessary in this context. Thus, the genetic improvement of biological control agents would better fit in an inundative strategy, rather than in a classical biological control strategy (Lommen et al., 2017).

\section{Inoculative Strategy}

The inoculative strategy consists in an intentional release of biological control agents aiming to favor the establishment of predators in the agroecosystem so that it acts for an extended period on target pest populations (Eilenberg et al., 2001). This strategy differs from the inundative strategy by the expectation that the biological control agent will control the pest after the agent's reproduction. Therefore, it is necessary that the biological 
control agent reproduces in the agricultural environment. The stability of the predator-prey cycle is therefore a foundation of this approach. For the same biocontrol agent, selection on different traits will have consequences on predator-prey dynamics (Nachappa et al., 2011). For instance, Nachappa et al. (2011) noted that the selection for high voracity in $P$. persimilis is more in line with inundative biocontrol objectives, while selection for high olfactory response and high conversion rate meet the needs of inoculative control. In the case of zoophytophagous predators, a specialization on animal resources could be positively correlated with a strong olfactory response to HIPVs or increased fertility. Whether these correlations are genetic or not, they would improve the performance of zoophytophagous predators in the context of an inoculative strategy.

The stability of the trait-selected populations on the longterm is also a key issue in preserving the biological control services quality of the selected strains. The ability of the selected strains to adapt to their new environment can be compromised by the limited genetic variation arising from the selection process (Hopper et al., 1993; Fauvergue et al., 2012; Roderick et al., 2012). The establishment of the released individuals in the agroecosystem is needed to meet the requirements of the inoculative biological strategy. Hence, genetic improvement of biological control agents may in fact, have a negative impact on this important aspect (Hopper et al., 1993). Moreover, the release of zoophytophagous predators from the selected population will introduce their genes into the genetic pool of local populations. These genes could be conserved or not by natural selection (Hufbauer and Roderick, 2005). Thus, the effect of the selection may decrease over time without repeated introductions of the selected strains. In addition, the introduction of new genes in local populations could have consequences for the evolution of local populations (Thrall et al., 2011; Richardson et al., 2014).

\section{Conservation Strategy}

In agroecosystems, agricultural practices can act as a selective force on arthropods, ultimately modifying local populations (Thrall et al., 2011). The evolution in agroecosystems can occur at an ecological time scale (Lankau, 2011; Palkovacs et al., 2011; Sih et al., 2011; Sih, 2013). This evolution, which often is very rapid under the influence of anthropogenic action, should no longer be neglected in pest management programs (Ashley et al., 2003; Stockwell et al., 2003; Lankau, 2011; Sih et al., 2011; Sih, 2013). Evolutionary processes can be concretely utilized using approaches that influence, genetic variability, selection, connectivity and gene flow (Lankau, 2011). For example, growers use pesticides alterations to prevent the development of resistance (Thrall et al., 2011). Such approaches maintain adequate genetic variability in populations and varying sources of selection (Hendry et al., 2011). However, even in alternation, pesticides may not prevent all types of selection (Thrall et al., 2011). Zoophytophagous predators may be threatened by chemical treatments either by direct effects on their survival and reproduction (Moser and Obrycki, 2009; Torres et al., 2010) or indirectly by a reduction in the prey's abundance (Kinkorová and Kocourek, 2000).
Agricultural practices (e.g., pesticide use, landscape management) could select for traits other than resistance. For instance, in the mullein bug's case, the spring generation females lay their eggs either on a herbaceous host (e.g., mullein plants) or on apple trees (McMullen and Jong, 1970). Host plant selection could be motivated by diet specialization (i.e., females preferably select sites that provide the optimal diet for their offspring), but it should consider host plants and prey phenology. Prey-specialized strains may remain on apple trees if prey populations are high, whereas plantspecialized strains are expected to move to herbaceous hosts to feed mainly on pollen (e.g., mullein plant). Consequently, nymphs emerging on apple trees in July (prey-specialized strains) may be negatively affected by insecticide use targeting pest species, as opposed to the nymphs that emerge on the herbaceous hosts outside the orchards (plant-specialized strains). Therefore, chemical treatments will become more threatening to beneficial individuals (from prey-specialized strains), rather than detrimental ones. This uncontrolled selection's process could quickly lead to undesirable changes in mullein bugs natural populations considering the high heritability of the diet specialization in this species (Dumont et al., 2016, 2017a). Ultimately, such changes in the populations' composition could lead to variations in benefits and risks associated with local mullein bug populations. This means that any type of management strategy, or conservative biocontrol program should be evaluated first in terms of "Would this action constitute a selective force? And, will the consequences improve or negatively affect the genetic pool of the resident zoophytophagous populations?.”

\section{OTHER RELATED LIMITS AND CHALLENGES}

There will always be some degree of crop damage risks associated with zoophytophagous predators. Environmental conditions modulate the benefits and risks associated with such predators. The objective of selection for zoophytophagous predators is to improve the benefit-damage ratio in the circumstances where these predators have an economic impact (positive or negative). Thus, the improvement of benefit-damage ratio must be significant to worth the costs of selecting and maintaining selected lines under breeding conditions.

Keeping selected strains in long-term breeding for the purpose of releasing in crop systems entails some challenges, such as maintaining the desired traits in rearing units over a long period. Artificial breeding conditions could favor undesirable changes in the reared populations and increase inbreeding. The process of selections should be repeated at certain intervals to introduce new genes in mass-reared populations. Furthermore, increased zoophagy may entail increased aggressiveness and cannibalistic behaviors (Dumont et al., 2017b). In turn, such a trait could complicate the massive production of biological control agents. Therefore, the production protocols should be adapted to take such kinds of changes into account. 


\section{CONCLUSIONS}

It appears that the status of zoophytophagous biocontrol agents is highly variable according to the ecological context (Gillespie and McGregor, 2000; Arnó et al., 2006; Perdikis et al., 2009; Calvo et al., 2012; Biondi et al., 2016). In turn, this status may change rapidly. The exploitation of plant and animal resources implies a variation in the behavioral, physiological and morphological traits of zoophytophagous species (Coll and Guershon, 2002). The abundant source of individual genetic variation in zoophytophagous predators offers a unique opportunity to modify populations by selecting traits and individuals more adequate for biological control purposes (Dumont et al., 2016, 2017a). Selected lines of biological control agents would improve their impact on pest populations by being more voracious, having more or less dispersal, higher levels of wasting prey (i.e., killed prey left unconsumed), and

\section{REFERENCES}

Adachi-Hagimori, T., Shibao, M., Tanaka, H., Seko, T., and Miura, K. (2011). Control of Myzus persicae and Lipaphis erysimi (Hemiptera: Aphididae) by adults and larvae of a flightless strain of Harmonia axyridis (Coleoptera: Coccinellidae) on non-heading Brassica cultivars in the greenhouse. Biocontrol 56, 207-213. doi: 10.1007/s10526-010-9327-5

Agrawal, A. A., Conner, J. K., Johnson, M. T., and Wallsgrove, R. (2002). Ecological genetics of an induced plant defense against herbivores: additive genetic variance and costs of phenotypic plasticity. Evolution 56, 2206-2213. doi: 10.1111/j.0014-3820.2002.tb00145.x

Albajes, R., and Alomar, O. (1999). "Use and potentialities of polyphagous predators," in Integrated Pest and Disease Management in Greenhouse Crops, eds R. Albajes, M. L. Gullino, J. C. van Lenteren, and Y. Elad (Dordrecht: Kluwer Academic Publishers), 265-275.

Alomar, O., and Albajes, R. (1996). "Greenhouse whitefly (Homoptera: Aleyrodidae) predation and tomato fruit injury by the zoophytophagous predator Dicyphus tamaninii (Heteroptera: Miridae)," in Zoophytophagous Heteroptera: Implications for Life History and Integrated Pest Management, eds O. Alomar, and R. N. Wiedenamnn (Lanham, MD: Thomas Say Publications), $155-177$.

Alomar, Ò., Goula, M., and Albajes, R. (2002). Colonisation of tomato fields by predatory mirid bugs (Hemiptera: Heteroptera) in northern Spain. Agric. Ecosyst. Environ. 89, 105-115. doi: 10.1016/S0167-8809(01)00322-X

Alomar, O., Riudavets, J., and Castañe, C. (2006). Macrolophus caliginosus in the biological control of Bemisia tabaci on greenhouse melons. Biol. Control 36, 154-162. doi: 10.1016/j.biocontrol.2005.08.010

Araújo, M. S., Bolnick, D. I., and Layman, C. A. (2011). The ecological causes of individual specialisation. Ecol. Lett. 14, 948-958. doi: $10.1111 / j .1461-0248.2011 .01662 . x$

Araújo, M. S., Bolnick, D. I., Martinelli, L. A., Giaretta, A. A., and Dos Reis, S. F. (2009). Individual-level diet variation in four species of Brazilian frogs. J. Anim. Ecol. 78, 848-856. doi: 10.1111/j.1365-2656.2009.01546.x

Arnó, J., Castañé, C., Riudavets, J., and Gabarra, R. (2006). Characterization of damage to tomato plants produced by the zoophytophagous predator Nesidiocoris tenuis. IOBC wprs Bulletin 29, 249.

Arnó, J., Castañé, C., Riudavets, J., and Gabarra, R. (2010). Risk of damage to tomato crops by the generalist zoophytophagous predator Nesidiocoris tenuis (Reuter)(Hemiptera: Miridae). Bull. Entomol. Res. 100, 105-115. doi: 10.1017/S0007485309006841

Ashley, M. V., Willson, M. F., Pergams, O. R., O’Dowd, D. J., Gende, S. M., and Brown, J. S. (2003). Evolutionarily enlightened management. Biol. Conserv. 111, 115-123. doi: 10.1016/S0006-3207(02)00279-3

Aubry, O., Cormier, D., Chouinard, G., and Lucas, E. (2015). Influence of plant, animal and mixed resources on development of the zoophytophagous plant a stronger numerical response. The benefits of an omnivorous predator over a strict predator should not be lost. Furthermore, agricultural practices could generate evolution/selection of local populations (Thrall et al., 2011). As a result these practices may influence the ecosystem services and disservices associated with zoophytophagous predators.

\section{AUTHOR CONTRIBUTIONS}

All authors contributed equally to the writing and editing of the text. The example on mullein bug was drawn by $\mathrm{OA}$ and $\mathrm{FD}$ in their PhD thesis, which was supervised by EL.

\section{ACKNOWLEDGMENTS}

We are grateful to Stéphane Duong and Laura Chouinard-Thuly for the linguistic revision of the manuscript.

bug Campylomma verbasci (Hemiptera: Miridae). Biocontrol. Sci. Techn. 25, 1426-1442. doi: 10.1080/09583157.2015.1061098

Aubry, O., Cormier, D., Chouinard, G., and Lucas, E. (2016). Phytophagy by the mullein bug (Hemiptera: Miridae) on apples: feeding behaviour and fruit damage. J. Econ. Entomol. 109, 2463-2471. doi: 10.1093/jee/tow209

Aubry, O., Cormier, D., Chouinard, G., and Lucas, E. (2017). Influence of extraguild prey and intraguild predators on the phytophagy of the zoophytophagous bug Campylomma verbasci. J. Pest Sci. 90, 287-297. doi: 10.1007/s10340-016-0765-4

Baya, J. M., Sithanantham, S., Gitonga, L. M., Osir, E. O., and Agong, S. G. (2007). Scope for genetic enhancement of the parasitisation potential of four native strains of Trichogrammatoidea sp. nr. lutea Girault (Hymenoptera: Trichogrammatidae) in Kenya. Biocontrol Sci. Technol. 17, 743-755. doi: 10.1080/09583150701488669

Beitia, F., Asis, J.P., De Pedro, L., Goula, M, and Tormos, J. (2016). Importance of feeding behaviour on life cycle in the zoophytophagous bug Dicyphus geniculatus. Bull. Insectol. 69, 173-180.

Bennett, J. A., Gillespie, D. R., Shipp, J. L., and Vanlaerhoven, S. L. (2009). Foraging strategies and patch distributions: intraguild interactions between Dicyphus hesperus and Encarsia formosa. Ecol. Entomol. 34, 58-65. doi: 10.1111/j.1365-2311.2008.01043.x

Bernays, E., and Graham, M. (1988). On the evolution of host specificity in phytophagous arthropods. Ecology 69, 886-892. doi: 10.2307/1941237

Bernays, E. A. (1996). Selective attention and host-plant specialization. Entomol. Exp. Appl. 80, 125-131. doi: 10.1111/j.1570-7458.1996.tb00902.x

Bernays, E. A., and Bright, K. L. (2001). Food choice causes interrupted feeding in the generalist grasshopper Schistocerca americana: further evidence for inefficient decision-making. J. Insect Physiol. 47, 63-71. doi: 10.1016/S0022-1910(00)00090-1

Bernays, E. A., Singer, M. S., and Rodrigues, D. (2004). Foraging in nature: foraging efficiency and attentiveness in caterpillars with different diet breadths. Ecol. Entomol. 29, 389-397. doi: 10.1111/j.0307-6946.2004.00615.x

Bernays, E. A., and Wcislo, W. T. (1994). Sensory capabilities, information processing, and resource specialization. Q. Rev. Biol. 69, 187-204. doi: $10.1086 / 418539$

Biondi, A., Zappalà, L., Di Mauro, A., Garzia, G. T., Russo, A., Desneux, N., et al. (2016). Can alternative host plant and prey affect phytophagy and biological control by the zoophytophagous mirid Nesidiocoris tenuis? Biocontrol 61, 79-90. doi: 10.1007/s10526-015-9700-5

Bolnick, D. I. (2001). Intraspecific competition favours niche width expansion in Drosophila melanogaster. Nature 410:463. doi: 10.1038/35068555

Bolnick, D. I., Amarasekare, P., Araújo, M. S., Bürger, R., Levine, J. M., Novak, M., et al. (2011). Why intraspecific trait variation matters in community ecology. Trends Ecol. Evol. 26, 183-192. doi: 10.1016/j.tree.2011. 01.009 
Bolnick, D. I., Svanbäck, R., Fordyce, J. A., Yang, L. H., Davis, J. M., Hulsey, C. D., et al. (2002). The ecology of individuals: incidence and implications of individual specialization. Am. Nat. 161, 1-28. doi: 10.1086/343878

Bompard, A., Jaworski, C. C., Bearez, P., and Desneux, N. (2013). Sharing a predator: can an invasive alien pest affect the predation on a local pest? Popul. Ecol. 55, 433-440. doi: 10.1007/s10144-013-0371-8

Bouagga, S., Urbaneja, A., Rambla, J. L., Flors, V., Granell, A., Jaques, J. A., et al. (2018b). Zoophytophagous mirids provide pest control by inducing direct defences, antixenosis and attraction to parasitoids in sweet pepper plants. Pest Manag. Sci. 74, 1286-1296. doi: 10.1002/ps.4838

Bouagga, S., Urbaneja, A., Rambla, J. L., Granell, A., and Pérez-Hedo, M. (2018a). Orius laevigatus strengthens its role as a biological control agent by inducing plant defenses. J. Pest Sci. 91, 55-64. doi: 10.1007/s10340-017-0886-4

Boyd, D. W., Cohen, A. C., and Alverson, D. R. (2002). Digestive enzymes and stylet morphology of Deraeocoris nebulosus (Hemiptera: Miriadae), a predacious plant bug. Ann. Entomol. Soc. Am. 95, 395-401. doi: 10.1603/00138746(2002)095[0395:DEASMO]2.0.CO;2

Calvo, F. J., Lorente, M. J., Stansly, P. A., and Belda, J. E. (2012). Preplant release of Nesidiocoris tenuis and supplementary tactics for control of Tuta absoluta and Bemisa tabaci in greenhouse tomato. Entomol. Exp. Appl. 143, 111-119. doi: 10.1111/j.1570-7458.2012.01238.x

Calvo, J., Bolckmans, K., Stansly, P. A., and Urbaneja, A. (2009). Predation by Nesidiocoris tenuis on Bemisia tabaci and injury to tomato. BioControl 54, 237-246. doi: 10.1007/s10526-008-9164-y

Castañé, C., Alomar, O., and Riudavets, J. (1996). Management of western flower thrips on cucumber with Dicyphus tamaninii (Heteroptera: Miridae). Biological control 7, 114-120. doi: 10.1006/bcon.1996.0073

Castañe, C., Arno, J., Gabarra, R., and Alomar, O. (2011). Plant damage to vegetable crops by zoophytophagous mirid predators. Biol. Control 59, 22-29. doi: 10.1016/j.biocontrol.2011.03.007

Castañé, C., Riudavets, J., and Alomar, O. (2009). Effect of the generalist predator Dicyphus tamaninii on mixed populations of greenhouse whitefly and western flower thrips in greenhouse cucumbers. Bol. Sanid. Veg. Plagas 35, 29-37.

Clutton-Brock, T., and Sheldon, B. C. (2010). Individuals and populations: the role of long-term, individual-based studies of animals in ecology and evolutionary biology. Trends Ecol. Evol. 25, 562-573. doi: 10.1016/j.tree.2010.08.002

Cobben, R. H. (1978). Evolutionary Trends in Heteroptera. Part II. MouthpartStructures and Feeding Strategies. Wageningen, Veenman: Mededelingen Landbouwhogeschool Wageningen.

Coll, M. (1996). Feeding and ovipositing on plants by an omnivorous insect predator. Oecologia 105, 214-220. doi: 10.1007/BF00328549

Coll, M., de Mendoza, L. G., and Roderick, G. K. (1994). Population structure of a predatory beetle: the influence of gene flow for intertrophic level interactions. Heredity 72, 228-236. doi: 10.1038/hdy.1994.32

Coll, M., and Guershon, M. (2002). Omnivory in terrestrial arthropods: mixing plant and prey diets. Annu. Rev. Entomol. 47, 267-297. doi: 10.1146/annurev.ento.47.091201.145209

Cooper, W. E. (2002). Convergent evolution of plant chemical discrimination by omnivorous and herbivorous scleroglosan lizards. J. Zool. 257, 53-66. doi: $10.1017 /$ S0952836902000651

Cooper, W. E., and Vitt, L. J. (2002). Distribution, extent, and evolution of plant consumption by lizards. J. Zool. 257, 487-517. doi: $10.1017 /$ S0952836902001085

Cottrell, T. E., and Yeargan, K. V. (1998). Effect of pollen on Coleomegilla maculata (Coleoptera: Coccinellidae) population density, predation, and cannibalism in sweet corn. Environ. Entomol. 27, 1402-1410. doi: 10.1093/ee/27.6.1402

Dall, S. R., Bell, A. M., Bolnick, D. I., and Ratnieks, F. L. (2012). An evolutionary ecology of individual differences. Ecol. Lett. 15, 1189-1198. doi: $10.1111 / j .1461-0248.2012 .01846 . x$

Dall, S. R., Houston, A. I., and McNamara, J. M. (2004). The behavioural ecology of personality: consistent individual differences from an adaptive perspective. Ecol. Lett. 7, 734-739. doi: 10.1111/j.1461-0248.2004.00618.x

De Backer, L., Megido, R. C., Fauconnier, M. L., Brostaux, Y., Francis, F., and Verheggen, F. (2015). Tuta absoluta-induced plant volatiles: attractiveness towards the generalist predator Macrolophus pygmaeus. Arthropod Plant Interact. 9, 465-476. doi: 10.1007/s11829-015-9388-6

Denno, R. F., and Fagan, W. F. (2003). Might nitrogen limitation promote omnivory among carnivorous arthropods? Ecology 84, 2522-2531. doi: 10.1890/02-0370
Desneux, N., Luna, M. G., Guillemaud, T., and Urbaneja, A. (2011). The invasive South American tomato pinworm, Tuta absoluta, continues to spread in AfroEurasia and beyond: the new threat to tomato world production. J. Pest Sci. 84, 403-408. doi: 10.1007/s10340-011-0398-6

DeWitt, T. J., Sih, A., and Wilson, D. S. (1998). Costs and limits of phenotypic plasticity. Trends Ecol. Evol. 13, 77-81. doi: 10.1016/S0169-5347(97)01274-3

Diehl, S., and Feißel, M. (2000). Effects of enrichment on three-level food chains with omnivory. Am. Nat. 155, 200-218. doi: 10.1086/303319

Dingemanse, N. J., Kazem, A. J., Réale, D., and Wright, J. (2010). Behavioural reaction norms: animal personality meets individual plasticity. Trends Ecol. Evol. 25, 81-89. doi: 10.1016/j.tree.2009.07.013

Dingemanse, N. J., and Wolf, M. (2013). Between-individual differences in behavioural plasticity within populations: causes and consequences. Anim. Behav. 85, 1031-1039. doi: 10.1016/j.anbehav.2012.12.032

Dumont, F., Lucas, E., and Réale, D. (2016). Evidence of genetic basis of zoophagy and nymphal developmental time in isogroup lines of the zoophytophagous mullein bug, Campylomma verbasci. Biocontrol 61, 425-435. doi: 10.1007/s10526-016-9721-8

Dumont, F., Lucas, E., and Réale, D. (2017a). Coexistence of zoophytophagous and phytozoophagous strategies linked to genotypic diet specialization in plant bug. PLoS ONE 12:e0176369. doi: 10.1371/journal.pone.0176369

Dumont, F., Réale, D., and Lucas, E. (2017b). Isogroup selection to optimize biocontrol increases cannibalism in omnivorous (zoophytophagous) bugs. Insects 8:74. doi: 10.3390/insects8030074

Eilenberg, J., Hajek, A., and Lomer, C. (2001). Suggestions for unifying the terminology in biological control. Biocontrol 46, 387-400. doi: 10.1023/A:1014193329979

Ellner, S. P. (2013). Rapid evolution: from genes to communities, and back again? Funct. Ecol. 27, 1087-1099. doi: 10.1111/1365-2435.12174

Eubanks, M. D. (2005). "Predaceous herbivores and herbivorous predators: the biology of omnivores and the ecology of omnivore-prey interactions," in Ecology of Predator-Prey Interactions, eds P. Barbosa, and I. Castellanos (New York, NY: Oxford University Press), 3-16.

Eubanks, M. D., and Denno, R. F. (1999). The ecological consequences of variation in plants and prey for an omnivorous insect. Ecology 80, 1253-1266. doi: 10.1890/0012-9658(1999)080[1253:TECOVI]2.0.CO;2

Eubanks, M. D., and Denno, R. F. (2000a). Health food versus fast food: the effects of prey quality and mobility on prey selection by a generalist predator and indirect interactions among prey species. Ecol. Entomol. 25, 140-146. doi: $10.1046 / j .1365-2311.2000 .00243 . x$

Eubanks, M. D., and Denno, R. F. (2000b). Host plants mediate omnivoreherbivore interactions and influence prey suppression. Ecology 81, 936-947. doi: 10.1890/0012-9658(2000)081[0936:HPMOHI]2.0.CO;2

Eubanks, M. D., and Styrsky, J. D. (2005). "Effects of plant feeding on the performance of omnivorous predators," in Plant-Provided Food and HerbivoreCarnivore Interactions, eds F. L. Wackers, P. C. J. van Rijn, and J. Bruin (New York, NY: Cambridge University Press), 148-177.

Eubanks, M. D., Styrsky, J. D., and Denno, R. F. (2003). The evolution of omnivory in heteropteran insects. Ecology 84, 2549-2556. doi: 10.1890/02-0396

Falconer, D. S., and Mackay, T. F. C. (1996). Introduction to Quantitative Genetics, 4th Edn. Harlow: Longman Sci. and Tech.

Fantinou, A. A., Perdikis, D. C., Labropoulos, P. D., and Maselou, D. A. (2009). Preference and consumption of Macrolophus pygmaeus preying on mixed instar assemblages of Myzus persicae. Biol. Control 51, 76-80. doi: 10.1016/j.biocontrol.2009.06.006

Fauvergue, X., Vercken, E., Malausa, T., and Hufbauer, R. A. (2012). The biology of small, introduced populations, with special reference to biological control. Evol. Appl. 5, 424-443. doi: 10.1111/j.1752-4571.2012. 00272.x

Fréchette, B., Rojo, S., Alomar, O., and Lucas, É. (2007). Intraguild predation between syrphids and mirids: who is the prey? Who is the predator? Biocontrol 52, 175. doi: 10.1007/s10526-006-9028-2

Gabarra, R., Alomar, O., Castañe, C., Goula, M., and Albajes, R. (2004). Movement of greenhouse whitefly and its predators between in- and outside of Mediterranean greenhouses. Agric. Ecosyst. Environ. 102, 341-348. doi: 10.1016/j.agee.2003.08.012

Garantonakis, N., Pappas, M. L., Varikou, K., Skiada, V., Broufas, G. D. Kavroulakis, N., et al. (2018). Tomato inoculation with the endophytic strain Fusarium solani $\mathrm{K}$ results in reduced feeding damage by the 
zoophytophagous predator Nesidiocoris tenuis. Front. Ecol. Evol. 6:126. doi: $10.3389 /$ fevo.2018.00126

Gillespie, D.R., VanLaerhoven, S.L., McGregor, R.R., Chan, S., and Roitberg, B.D. (2012). Plant feeding in an omnivorous mirid, Dicyphus hersperus: why plant context matters. Psyche 2012, 1-12. doi: 10.1155/2012/495805

Gillespie, D. R., and McGregor, R. R. (2000). The functions of plant feeding in the omnivorous predator Dicyphus hesperus: water places limits on predation. Ecol. Entomol. 25, 380-386. doi: 10.1046/j.1365-2311.2000.00285.x

Gordon, H. T. (1961). Nutritional factors in insect resistance to chemicals. Annu. Rev. Entomol. 6, 27-54. doi: 10.1146/annurev.en.06.010161.000331

Grimm, V. (1999). Ten years of individual-based modelling in ecology: what have we learned and what could we learn in the future? Ecol. Modell. 115, 129-148. doi: 10.1016/S0304-3800(98)00188-4

Grosman, A. H., Van Breemen, M., Holtz, A., Pallini, A., Rugama, A. M., Pengel, H., et al. (2005). Searching behaviour of an omnivorous predator for novel and native host plants of its herbivores: a study on arthropod colonization of eucalyptus in Brazil. Entomol. Exp. Appl. 116, 135-142. doi: 10.1111/j.1570-7458.2005.00307.x

Han, P., Dong, Y., Lavoir, A.V., Adamowicz, S., Bearez, P., Wajnberg, E., et al. (2015). Effect of plant nitrogen and water status on the foraging behaviour and fitness of an omnivorous arthropod. Ecol. Evol. 5, 5468-5477. doi: $10.1002 /$ ece 3.1788

Havron, A., Kenan, G., and Rosen, D. (1991). Selection for pesticide resistance in Aphytis: II. A. lingnanensis, a parasite of the California red scale. Entomol. Exp. Appl. 61, 229-235. doi: 10.1111/j.1570-7458.1991.tb01555.x

Hedrick, A. V., and Riechert, S. E. (1989). Genetically-based variation between two spider populations in foraging behaviour. Oecologia 80, 533-539. doi: 10.1007/BF00380078

Hendry, A. P., Kinnison, M. T., Heino, M., Day, T., Smith, T. B., Fitt, G., et al. (2011). Evolutionary principles and their practical application. Evol. Appl. 4, 159-183. doi: 10.1111/j.1752-4571.2010.00165.x

Holt, R. D., and Lawton, J. H. (1994). The ecological consequences of shared natural enemies. Annu. Rev. Ecol. Syst. 25, 495-520. doi: 10.1146/annurev.es.25.110194.002431

Holt, R. D., and Polis, G. A. (1997). A theoretical framework for intraguild predation. Am. Nat. 149, 745-764. doi: 10.1086/286018

Hopper, K. R., Roush, R. T., and Powell, W. (1993). Management of genetics of biological-control introductions. Annu. Rev. Entomol. 38, 27-51. doi: 10.1146/annurev.en.38.010193.000331

Hoy, M. A. (1976). Genetic improvement of insects: fact or fantasy. Environ. Entomol. 5, 833-839. doi: 10.1093/ee/5.5.833

Hoy, M. A. (1985). Recent advances in genetics and genetic improvement of the Phytoseiidae. Annu. Rev. Entomol. 30, 345-370. doi: 10.1146/annurev.en.30.010185.002021

Hoy, M. A. (1986). Use of genetic improvement in biological control. Agric. Ecosyst. Environ. 15, 109-119. doi: 10.1016/0167-8809(86)90084-8

Hoy, M. A. (1990). "Pesticide resistance in arthropod natural enemies: variability and selection responses," in Pesticide Resistance in Arthropods (Boston, MA: Springer), 203-236.

Hoy, M. A., and Knop, N. F. (1981). Selection for and genetic analysis of permethrin resistance in Metaseiulus occidentals: genetic improvement of a biocontrol agent. Entomol. Exp. Appl. 30, 10-18. doi: 10.1111/j.1570-7458.1981.tb03578.x

Hufbauer, R. A., and Roderick, G. K. (2005). Microevolution in biological control: mechanisms, patterns, and processes. Biol. Control 35, 227-239. doi: 10.1016/j.biocontrol.2005.04.004

Hughes, A. R., Inouye, B. D., Johnson, M. T., Underwood, N., and Vellend, M. (2008). Ecological consequences of genetic diversity. Ecol. Lett. 11, 609-623. doi: 10.1111/j.1461-0248.2008.01179.x

Ingegno, B. L., La-Spina, M., Jordan, M. J., Tavella, L., and Sanchez, J. A. (2016). Host plant perception and selection in the sibling species Macrolophus melanotoma and Macrolophus pygmaeus (Hemiptera: Miridae). J. Insect Behav. 29, 117-142. doi: 10.1007/s10905-016-9549-1

Jaenike, J., and Grimaldi, D. (1983). Genetic variation for host preference within and among populations of Drosophila tripunctata. Evolution 37, 1023-1033. doi: 10.1111/j.1558-5646.1983.tb05630.x

Jaworski, C. C., Bompard, A., Genies, L., Amiens-Desneux, E., and Desneux, N. (2013). Preference and prey switching in a generalist predator attacking local and invasive alien pests. PLoS ONE 8:e82231. doi: 10.1371/journal.pone.0082231

Jia, F., Margolies, D. C., Boyer, J. E., and Charlton, R. E. (2002). Genetic variation in foraging traits among inbred lines of a predatory mite. Heredity 89, 371. doi: $10.1038 /$ sj.hdy.6800145

Judson, O. P. (1994). The rise of the individual-based model in ecology. Trends Ecol. Evol. 9, 9-14. doi: 10.1016/0169-5347(94)90225-9

Kinkorová, J., and Kocourek, F. (2000). The effect of integrated pest management practices in an apple orchard on Heteroptera community structure and population dynamics. J. Appl. Entomol. 124, 381-385. doi: 10.1046/j.1439-0418.2000.00488.x

Kraaijeveld, A. R., Limentani, E. C., and Godfray, H. C. (2001). Basis of the trade-off between parasitoid resistance and larval competitive ability in Drosophila melanogaster. Proc. R. Soc. Lond. B Biol. Sci. 268, 259-261. doi: 10.1098/rspb.2000.1354

Kruitwagen, A., Beukeboom, L. W., and Wertheim, B. (2018). Optimization of native biocontrol agents, with parasitoids of the invasive pest $D$. suzukii as an example. Evol. Appl. 11, 1473-1497. doi: 10.1111/eva.12648

Lalonde, R. G., McGregor, R. R., and Gillespie, D. R. (1999). Plant-feeding by arthropod predators contributes to the stability of predator-prey population dynamics. Oikos 87, 603-608. doi: 10.2307/3546827

Lankau, R. A. (2011). Rapid evolutionary change and the coexistence of species. Annu. Rev. Ecol. Evol. Syst. 42, 335-354. doi: 10.1146/annurev-ecolsys-102710-145100

Lemos, W. P., Serrão, J. E., Zanuncio, J. C., Lacerda, M. C., Zanuncio, V. V., and Ribeiro, R. C. (2009). Body weight and protein content in the haemolymph of females of the zoophytophagous predator Brontocoris tabidus (Heteroptera: Pentatomidae) with different diets and ages. J. Plant Dis. Protect. 116, 218-222. doi: 10.1007/BF03356314

Lima-Espindola, J., Rodríguez-Leyva, E., Lomeli-Flores, J. R., and VelázquezGonzález, J. C. (2018). Does foraging experience affect the responses of the predator Dicyphus hesperus knight to prey-induced volatiles? Neotrop. Entomol. 47, 885-891. doi: 10.1007/s13744-017-0582-3

Lins, J. C., van Loon, J. J., Bueno, V. H., Lucas-Barbosa, D., Dicke, M., and van Lenteren, J. C. (2014). Response of the zoophytophagous predators Macrolophus pygmaeus and Nesidiocoris tenuis to volatiles of uninfested plants and to plants infested by prey or conspecifics. Biocontrol 59, 707-718. doi: 10.1007/s10526-014-9602-y

Lommen, S. T., Holness, T. C., van Kuik, A. J., de Jong, P. W., and Brakefield, P. M. (2013). Releases of a natural flightless strain of the ladybird beetle Adalia bipunctata reduce aphid-born honeydew beneath urban lime trees. Biocontrol 58, 195-204. doi: 10.1007/s10526-012-9478-7

Lommen, S. T., Jong, P. W., and Pannebakker, B. A. (2017). It is time to bridge the gap between exploring and exploiting: prospects for utilizing intraspecific genetic variation to optimize arthropods for augmentative pest control-a review. Entomol. Exp. Appl. 162, 108-123. doi: 10.1111/eea.12510

Lommen, S. T., Middendorp, C. W., Luijten, C. A., van Schelt, J., Brakefield, P. M., and de Jong, P. W. (2008). Natural flightless morphs of the ladybird beetle Adalia bipunctata improve biological control of aphids on single plants. Biol. Control 47, 340-346. doi: 10.1016/j.biocontrol.2008.09.002

Łomnicki, A. (1999). Individual-based models and the individualbased approach to population ecology. Ecol. Modell. 115, 191-198. doi: 10.1016/S0304-3800(98)00192-6

Lucas, E. (2012). "Intraguild interactions," in Ecology and Behaviour of the Ladybird Beetles (Coccinellidae), eds I. Dans, H. F. Hodek, van Emden, and A. Honek (Chichester: Blackweel Publishing), 343-374.

Lucas, E., and Alomar, O. (2001). Macrolophus caliginosus (Wagner) as an intraguild prey for the zoophytophagous Dicyphus tamaninii Wagner (Heteroptera: Miridae). Biol. Control 20, 147-152. doi: 10.1006/bcon.200 0.0890

Lucas, E., and Alomar, O. (2002). Impact of Macrolophus caliginosus presence on damage production by Dicyphus tamaninii (Heteroptera: Miridae) on tomato fruits. J. Econ. Entomol. 95, 1123-1129. doi: 10.1603/0022-0493-95. 6.1123

Lucas, É., Coderre, D., and Brodeur, J. (1998). Intraguild predation among aphid predators: characterization and influence of extraguild prey density. Ecology 79, 1084-1092. doi: 10.1890/0012-9658(1998)079[1084:IPAAPC] 2.0.CO;2 
Lucas, E., and Rosenheim, J. A. (2011). Influence of extraguild prey density on intraguild predation by heteropteran predators: a review of the evidence and a case study. Biol. Control 59, 61-67. doi: 10.1016/j.biocontrol.2011. 05.010

Maeda, T., and Liu, Y. (2006). Intraspecific variation in the olfactory response of the predatory mite Neoseiulus womersleyi Schicha (Acari: Phytoseiidae) to different amount of spider mite-infested plant volatiles. Appl. Entomol. Zool. 41, 209-215. doi: 10.1303/aez.2006.209

Maselou, D.A., Perdikis, D.C., Sabelis, M.W., and Fantinou, A.A. (2014). Use of plant resources by an omnivorous predator and the consequences for effective predation. Biol. Control 79, 92-100. doi: 10.1016/j.biocontrol.2014.09.002

Maupin, J. L., and Riechert, S. E. (2001). Superfluous killing in spiders: a consequence of adaptation to food-limited environments? Behav. Ecol. 12, 569-576. doi: 10.1093/beheco/12.5.569

McBrien, H. L., Judd, G. J. R., and Borden, J. H. (1997). Population suppression of Campylomma verbasci (Heteroptera: Miridae) by atmospheric permeation with synthetic sex pheromone. J. Econ. Entomol. 90, 801-808. doi: 10.1093/jee/90.3.801

McGregor, R. R., and Gillespie, D. R. (2005). Intraguild predation by the generalist predator Dicyphus hesperus on the parasitoid Encarsia formosa. Biocontrol Sci. Technol. 15, 219-227. doi: 10.1080/09583150400016076

McGregor, R. R., Gillespie, D. R., Quiring, D. M., and Foisy, M. R. (1999). Potential use of Dicyphus hesperus Knight (Heteroptera: Miridae) for biological control of pests of greenhouse tomatoes. Biol. Control 16, 104-110. doi: 10.1006/bcon.1999.0743

McMullen, R. D., and Jong, C. (1970). The biology and influence of pesticides on Campylomma verbasci (Heteroptera: Miridae). Can. Entomol. 102, 1390-1394. doi: 10.4039/Ent1021390-11

Mollá, O., González-Cabrera, J., and Urbaneja, A. (2011). The combined use of Bacillus thuringiensis and Nesidiocoris tenuis against the tomato borer Tuta absoluta. BioControl 56, 883-891. doi: 10.1007/s10526-011-9353-y

Montserrat, M., Albajes, R., and Castañé, C. (2000). Functional response of four heteropteran predators preying on greenhouse whitefly (Homoptera: Aleyrodidae) and western flower thrips (Thysanoptera: Thripidae). Environ. Entomol. 29, 1075-1082. doi: 10.1603/0046-225X-29.5.1075

Montserrat, M., Albajes, R., and Castañe, C. (2004). Behavioral responses of three plant-inhabiting predators to different prey densities. Biol. Control 30, 256-264. doi: 10.1016/j.biocontrol.2004.01.006

Moser, S. E., and Obrycki, J. J. (2009). Non-target effects of neonicotinoid seed treatments; mortality of coccinellid larvae related to zoophytophagy. Biol. Control 51, 487-492. doi: 10.1016/j.biocontrol.2009.09.001

Nachappa, P., Margolies, D. C., Nechols, J. R., and Campbell, J. F. (2011). Variation in predator foraging behaviour changes predator-prey spatio-temporal dynamics. Funct. Ecol. 25, 1309-1317. doi: 10.1111/j.1365-2435.2011.01892.x

Nachappa, P., Margolies, D. C., Nechols, J. R., and Morgan, T. J. (2010). Response of a complex foraging phenotype to artificial selection on its component traits. Evol. Ecol. 24, 631-655. doi: 10.1007/s10682-009-9318-0

Nakayama, S., Takatsuki, J. I., Seko, T., Ando, S., Miura, K., and Miyatake, T. (2013). Aphid consumption and residence time of larvae of flightless lady beetles, Harmonia axyridis (Coleoptera: Coccinellidae), on aphid-infested plants. Appl. Entomol. Zool. 48, 223-227. doi: 10.1007/s13355-013-0163-9

Naselli, M., Urbaneja, A., Siscaro, G., Jaques, J. A., Zappalà, L., Flors, V., et al. (2016). Stage-related defense response induction in tomato plants by Nesidiocoris tenuis. Int. J. Mol. Sci. 17, 1210. doi: 10.3390/ijms17081210

Palkovacs, E. P., Wasserman, B. A., and Kinnison, M. T. (2011). Eco-evolutionary trophic dynamics: loss of top predators drives trophic evolution and ecology of prey. PLoS ONE 6:e18879. doi: 10.1371/journal.pone.0018879

Pappas, M. L., Liapoura, M., Papantoniou, D., Avramidou, M., Kavroulakis, N., Weinhold, A., et al. (2018). The beneficial endophytic fungus Fusarium solani strain $\mathrm{K}$ alters tomato responses against spider mites to the benefit of the plant. Front. Plant Sci. 9:1603. doi: 10.3389/fpls.2018.01603

Pappas, M. L., Steppuhn, A., and Broufas, G. D. (2016). The role of phytophagy by predators in shaping plant interactions with their pests. Commun. Integr. Biol. 9:e0127251. doi: 10.1080/19420889.2016.1145320

Pappas, M. L., Steppuhn, A., Geuss, D., Topalidou, N., Zografou, A., Sabelis, M. W., et al. (2015). Beyond predation: the zoophytophagous predator Macrolophus pygmaeus induces tomato resistance against spider mites. PLoS ONE 10:e0127251. doi: 10.1371/journal.pone.0127251
Pels, B., and Sabelis, M. W. (1999). Local dynamics, overexploitation and predator dispersal in an acarine predator-prey system. Oikos 573-583. doi: $10.2307 / 3546662$

Perdikis, D., Fantinou, A., Garantonakis, N., Kitsis, P., Maselou, D., and Panagakis, S. (2009). Studies on the damage potential of the predator Nesidiocoris tenuis on tomato plants. Bull. Insectol. 62, 41-46.

Perdikis, D., Lucas, E., Garantonakis, N., Giatropoulos, A., Kitsis, P., Maselou, D., et al. (2014). Intraguild predation and sublethal interactions between two zoophytophagous mirids, Macrolophus pygmaeus and Nesidiocoris tenuis. Biol. Control 70, 35-41. doi: 10.1016/j.biocontrol.2013.12.003

Pérez-Hedo, M., Arias-Sanguino, Á. M., and Urbaneja, A. (2018). Induced tomato plant resistance against Tetranychus urticae triggered by the phytophagy of Nesidiocoris tenuis. Front. Plant Sci. 9:1419. doi: 10.3389/fpls.2018.01419

Perez-Hedo, M., Bouagga, S., Jaques, J.A., Flors, V., and Urbaneja, A. (2015b). Tomato plant responses to feeding behaviour of three zoophytophagous predators (Hemiptera: Miridae). Biol. Control 86, 46-51. doi: 10.1016/j.biocontrol.2015.04.006

Pérez-Hedo, M., Urbaneja-Bernat, P., Jaques, J. A., Flors, V., and Urbaneja, A. (2015a). Defensive plant responses induced by Nesidiocoris tenuis (Hemiptera: Miridae) on tomato plants. J. Pest Sci. 88, 543-554. doi: 10.1007/s10340-014-0640-0

Polis, G. A. (1991). Complex trophic interactions in deserts: an empirical critique of food-web theory. Am. Nat. 138, 123-155. doi: 10.1086/285208

Portillo, N., Alomar, O., and Wäckers, F. (2012). Nectarivory by the planttissue feeding predator Macrolophus pygmaeus Rambur (Heteroptera: Miridae): nutritional redundancy or nutritional benefit?. J. Insect Physiol. 58, 397-401. doi: 10.1016/j.jinsphys.2011.12.013

Preisser, E. L., Bolnick, D. I., and Benard, M. F. (2005). Scared to death? The effects of intimidation and consumption in predator-prey interactions. Ecology 86, 501-509. doi: 10.1890/04-0719

Pruitt, J. N., and Ferrari, M. C. (2011). Intraspecific trait variants determine the nature of interspecific interactions in a habitat-forming species. Ecology 92 1902-1908. doi: 10.1890/11-0701.1

Pruitt, N., and Riechert, S. E. (2012). The ecological consequences of temperament in spiders. Curr. Zool. 58, 589-596. doi: 10.1093/czoolo/58.4.589

Réale, D., Dingemanse, N. J., Kazem, A. J., and Wright, J. (2010a). Evolutionary and ecological approaches to the study of personality. Philos. Trans. R. Soc. Lond. B Biol. Sci. 365, 3937-3946. doi: 10.1098/rstb.2010.0222

Réale, D., Garant, D., Humphries, M. M., Bergeron, P., Careau, V., and Montiglio, P. O. (2010b). Personality and the emergence of the pace-of-life syndrome concept at the population level. Philos. Trans. R. Soc. B Biol. Sci. 365, 4051-4063. doi: $10.1098 /$ rstb.2010.0208

Réale, D., Reader, S. M., Sol, D., McDougall, P. T., and Dingemanse, N. J. (2007). Integrating animal temperament within ecology and evolution. Biol. Rev. 82, 291-318. doi: 10.1111/j.1469-185X.2007.00010.x

Richardson, J. L., Urban, M. C., Bolnick, D. I., and Skelly, D. K. (2014). Microgeographic adaptation and the spatial scale of evolution. Trends Ecol. Evol. 29, 165-176. doi: 10.1016/j.tree.2014.01.002

Riechert, S. E., and Hall, R. F. (2000). Local population success in heterogeneous habitats: reciprocal transplant experiments completed on a desert spider. J. Evol. Biol. 13, 541-550. doi: 10.1046/j.1420-9101.2000.00176.x

Riechert, S. E., and Hedrick, A. V. (1993). A test for correlations among fitnesslinked behavioural traits in the spider Agelenopsis aperta (Araneae, Agelenidae). Anim. Behav. 46, 669-675. doi: 10.1006/anbe.1993.1243

Rim, H., Uefune, M., Ozawa, R., Yoneya, K., and Takabayashi, J. (2017). Experience of plant infestation by the omnivorous arthropod Nesidiocoris tenuis affects its subsequent responses to prey-infested plant volatiles. Biocontrol 62, 233-242. doi: 10.1007/s10526-017-9791-2

Robinson, B. W., and Wilson, D. S. (1998). Optimal foraging, specialization, and a solution to Liem's paradox. Am. Nat. 151, 223-235. doi: 10.1086/286113

Roderick, G. K., Hufbauer, R., and Navajas, M. (2012). Evolution and biological control. Evol. Appl. 5, 419-423. doi: 10.1111/j.1752-4571.2012.00281.x

Roitberg, B.D., Gillespie, D.R., Quiring, D.M., Alma, C.R., Jenner, W.H., Perry, J., et al. (2005). The cost of being on omnivore: mandible wear from plant feeding in a true bug. Naturwissenschaften 92: 431-434. doi: 10.1007/s00114-005-0013-x

Rosenheim, J. A., and Harmon, J. P. (2006). "The influence of intraguild predation on the suppression of a shared prey population: an empirical reassessment," 
in Trophic and Guild in Biological Interactions Control (Dordrecht: Springer), $1-20$.

Rosenheim, J. A., and Hoy, M. A. (1988). Genetic improvement of a parasitoid biological control agent: artificial selection for insecticide resistance in Aphylis melinus (Hymenopera: Aphelinidae). J. Econ. Entomol. 81, 1539-1550. doi: 10.1093/jee/81.6.1539

Rosenheim, J. A., Wilhoit, L. R., and Armer, C. A. (1993). Influence of intraguild predation among generalist insect predators on the suppression of an herbivore population. Oecologia 96, 439-449. doi: 10.1007/BF00317517

Rouchet, R., and Vorburger, C. (2014). Experimental evolution of parasitoid infectivity on symbiont-protected hosts leads to the emergence of genotype specificity. Evolution 68, 1607-1616. doi: 10.1111/evo.12377

Salamero, A., Gabarra, R., and Albajes, R. (1987). Observations on the predatory and phytophagous habits of Dicyphus tamaninii Wagner (Heteroptera; Miridae). Bull. SROP. 10, 165-169.

Salas Gervassio, N. G., Pérez-Hedo, M., Luna, M. G., and Urbaneja, A. (2017). Intraguild predation and competitive displacement between Nesidiocoris tenuis and Dicyphus maroccanus, two biological control agents in tomato pests. Insect Sci. 24, 809-817. doi: 10.1111/1744-7917.12361

Sanchez, J. A. (2008). Factors influencing zoophytophagy in the plant bug Nesidiocoris tenuis (Heteroptera: Miridae). Agric. For. Entomol. 10, 75-80. doi: 10.1111/j.1461-9563.2007.00357.x

Sanchez, J. A., Gillespie, D. R., and McGregor, R. R. (2004). Plant preference in relation to life history traits in the zoophytophagous predator Dicyphus hesperus. Entomol. Exp. Appl. 112, 7-19. doi: 10.1111/j.0013-8703.2004.00174.x

Sánchez, J. A., and Lacasa, A. (2008). Impact of the zoophytophagous plant bug Nesidiocoris tenuis (Heteroptera: Miridae) on tomato yield. J. Econ. Entomol. 101, 1864-1870. doi: 10.1603/0022-0493-101.6.1864

Sanchez, J. A., La-Spina, M., and Lacasa, A. (2014). Numerical response of Nesidiocoris tenuis (Hemiptera: Miridae) preying on Tuta absoluta (Lepidoptera: Gelechiidae) in tomato crops. Eur. J. Entomol. 111, 387-395. doi: 10.14411 eje.2014.041

Schaefer, C. W., and Panizzi, A. R. (2000). "Economic importance of heteroptera: a general view," in Heteroptera of Economic Importance, eds C. W. Schaefer, and A. R. Panizzi (Boca Raton, FL: CRC Press LLC), 657-693.

Scheiner, S. M., and Berrigan, D. (1998). The genetics of phenotypic plasticity. VIII. The cost of plasticity in Daphnia pulex. Evolution 52, 368-378. doi: 10.1111/j.1558-5646.1998.tb01638.x

Seagraves, M. P., and Lundgren, J. G. (2010). Oviposition response by Orius insidiosus (Hemiptera: Anthocoridae) to plant quality and prey availability. Biol. Control 55, 174-177. doi: 10.1016/j.biocontrol.2010.06.013

Segal, D., and Glazer, I. (2000). Genetics for improving biological control agents: the case of entomopathogenic nematodes. Crop Protect. 19, 685-689. doi: 10.1016/S0261-2194(00)00091-0

Seko, T., and Miura, K. (2009). Effects of artificial selection for reduced flight ability on survival rate and fecundity of Harmonia axyridis (Pallas) (Coleoptera: Coccinellidae). Appl. Entomol. Zool. 44, 587-594. doi: 10.1303/aez.2009.587

Seko, T., Sumi, A., Nakano, A., Kameshiro, M., Kaneda, T., and Miura, K. (2014). Suppression of aphids by augmentative release of larvae of flightless Harmonia axyridis. J. Appl. Entomol. 138, 326-337. doi: 10.1111/jen.12090

Shapiro-Ilan, D. I., Stuart, R., and McCoy, C. W. (2003). Comparison of beneficial traits among strains of the entomopathogenic nematode, Steinernema carpocapsae, for control of Curculio caryae (Coleoptera: Curculionidae). Biol. Control 28, 129-136. doi: 10.1016/S1049-9644(03)00030-6

Sih, A. (2013). Understanding variation in behavioural responses to humaninduced rapid environmental change: a conceptual overview. Anim. Behav. 85, 1077-1088. doi: 10.1016/j.anbehav.2013.02.017

Sih, A., Bell, A., and Johnson, J. C. (2004). Behavioral syndromes: an ecological and evolutionary overview. Trends Ecol. Evol. 19, 372-378. doi: 10.1016/j.tree.2004.04.009

Sih, A., Cote, J., Evans, M., Fogarty, S., and Pruitt, J. (2012). Ecological implications of behavioural syndromes. Ecol. Lett. 15, 278-289. doi: 10.1111/j.1461-0248.2011.01731.x

Sih, A., Ferrari, M. C., and Harris, D. J. (2011). Evolution and behavioural responses to human-induced rapid environmental change. Evol. Appl. 4, 367-387. doi: 10.1111/j.1752-4571.2010.00166.x

Silva, D. B., Bueno, V. H., Van Loon, J. J., Peñaflor, M. F. G., Bento, J. M. S., and Van Lenteren, J. C. (2018). Attraction of three mirid predators to tomato infested by both the tomato leaf mining moth Tuta absoluta and the Whitefly Bemisia tabaci. J. Chem. Ecol. 44, 29-39. doi: 10.1007/s10886-017-0909-x

Singer, M. S., and Bernays, E. A. (2003). Understanding omnivory needs a behavioural perspective. Ecology 84, 2532-2537. doi: 10.1890/02-0397

Sinia, A., Roitberg, B., McGregor, R. R., and Gillespie, D. R. (2004). Prey feeding increases water stress in the omnivorous predator Dicyphus hesperus. Entomol. Exp. Appl. 110, 243-248. doi: 10.1111/j.0013-8703.2004.00145.x

Snyder, W. E., and Ives, A. R. (2003). Interactions between specialist and generalist natural enemies: parasitoids, predators, and pea aphid biocontrol. Ecology 84, 91-107. doi: 10.1890/0012-9658(2003)084[0091:IBSAGN]2.0.CO;2

Sokolowski, M. B. (2001). Drosophila: genetics meets behaviour. Nature Reviews Genetics 2, 879. doi: 10.1038/35098592

Start, D., and Gilbert, B. (2017). Predator personality structures prey communities and trophic cascades. Ecol. Lett. 20, 366-374. doi: 10.1111/ele.12735

Stockwell, C. A., Hendry, A. P., and Kinnison, M. T. (2003). Contemporary evolution meets conservation biology. Trends Ecol. Evol. 18, 94-101. doi: 10.1016/S0169-5347(02)00044-7

Svanbäck, R., and Bolnick, D. I. (2005). Intraspecific competition affects the strength of individual specialization: an optimal diet theory method. Evol. Ecol. Res. 7, 993-1012.

Svanbäck, R., and Bolnick, D. I. (2007). Intraspecific competition drives increased resource use diversity within a natural population. Proc. R. Soc. Lond. B Biol. Sci. 274, 839-844. doi: 10.1098/rspb.2006.0198

Symondson, W.O.C., Sunderland, K.D., and Greenstone, M.H. (2002). Can generalist predators be effective biocontrol agents? Annu. Rev. Entomol. 47, 561-594. doi: 10.1146/annurev.ento.47.091201.145240

Tabone, E., Bardon, C., Desneux, N., and Wajnberg, E. (2010). Parasitism of different Trichogramma species and strains on Plutella xylostella L. on greenhouse cauliflower. J. Pest Sci. 83, 251-256. doi: 10.1007/s10340-010-0292-7

Thistlewood, H. M. A., Borden, J. H., Smith, R. F., Pierce, H. D. Jr., and McMullen, R. D. (1989). Evidence for a sex pheromone in the mullein bug, Campylomma verbasci (Heteroptera: Miridae). Can. Entomol. 121, 737-744. doi: 10.4039/Ent121737-9

Thrall, P. H., Oakeshott, J. G., Fitt, G., Southerton, S., Burdon, J. J., Sheppard, A., et al. (2011). Evolution in agriculture: the application of evolutionary approaches to the management of biotic interactions in agro-ecosystems. Evol. Appl. 4, 200-215. doi: 10.1111/j.1752-4571.2010.00179.x

Torres, J. B., Barros, E. M., Coelho, R. R., and Pimentel, R. M. (2010). Zoophytophagous pentatomids feeding on plants and implications for biological control. Arthropod Plant Interact. 4, 219-227. doi: 10.1007/s11829-010-9095-2

Toscano, B. J., Gownaris, N. J., Heerhartz, S. M., and Monaco, C. J. (2016), Personality, foraging behaviour and specialization: integrating behavioural and food web ecology at the individual level. Oecologia 182, 55-69. doi: 10.1007/s00442-016-3648-8

Tourniaire, R., Ferran, A., Giuge, L., Piotte, C., and Gambier, J. (2000). A natural flightless mutation in the ladybird, Harmonia axyridis. Entomol. Exp. Appl. 96, 33-38. doi: 10.1046/j.1570-7458.2000.00676.x

Urbaneja, A., Montón, H., and Mollá, O. (2009). Suitability of the tomato borer Tuta absoluta as prey for Macrolophus pygmaeus and Nesidiocoris tenuis. J. Appl. Entomol. 133, 292-296. doi: 10.1111/j.1439-0418.2008.01319.x

Urbaneja-Bernat, P., Tena, A., Bolckmans, K., and Urbaneja, A. (2013). Sugar as nutritional supplement for the zoophytophagous predator Nesidiocoris tenuis. Biocontrol 58, 57-64. doi: 10.1007/s10526-012-9466-y

Vance-Chalcraft, H. D., Rosenheim, J. A., Vonesh, J. R., Osenberg, C. W., and Sih, A. (2007). The influence of intraguild predation on prey suppression and prey release: a meta-analysis. Ecology 88, 2689-2696. doi: 10.1890/06-1869.1

Waldbauer, G. P., and Friedman, S. (1991). Self-selection of optimal diets by insects. Аnnu. Rev. Entomol. 36, 43-63. doi: 10.1146/annurev.en.36.010191.000355

Wheeler, A. G. (2000). "Predacious plant bugs (Miridae),". in Heteroptera of Economic Importance, eds C. W. Schaefer, and A. R. Panizzi (Boca Raton, FL: CRC Press LLC), 657-693.

Wheeler, A. G. (2001). Biology of the Plant Bugs (Hemiptera: Miridae). Pests, Predators, Opportunists. Ithaca, NY: Cornell University Press.

Wiedenmann, R. N., and Wilson, L. T. (1996). "Zoophytophagous heteroptera: summary and future research needs," in Zoophytophagous Heteroptera: 
Implications for Life History and Integrated Pest Management, eds O. Alomar, and R. N. Wiedenamnn (Lanham, MD: Thomas Say Publications), 190-202.

Wilson, D. S., and Yoshimura, J. (1994). On the coexistence of specialists and generalists. Am. Nat. 144, 692-707. doi: 10.1086/285702

Wolf, M., and Weissing, F. J. (2012). Animal personalities: consequences for ecology and evolution. Trends Ecol. Evol. 27, 452-461. doi: 10.1016/j.tree.2012.05.001

Zappala, L., Biondi, A., Alma, A., Al-Jboory, I. J., Arno, J., Bayram, A., et al. (2013). Natural enemies of the South American moth, Tuta absoluta, in Europe, North Africa and Middle East, and their potential use in pest control strategies. J. Pest Sci. 86, 635-647. doi: 10.1007/s10340-013-0531-9
Conflict of Interest Statement: The authors declare that the research was conducted in the absence of any commercial or financial relationships that could be construed as a potential conflict of interest.

Copyright (c) 2018 Dumont, Aubry and Lucas. This is an open-access article distributed under the terms of the Creative Commons Attribution License (CC BY). The use, distribution or reproduction in other forums is permitted, provided the original author(s) and the copyright owner(s) are credited and that the original publication in this journal is cited, in accordance with accepted academic practice. No use, distribution or reproduction is permitted which does not comply with these terms. 